\title{
Peran Padang Lamun Terhadap Hewan Asosiasi di Perairan Indonesia
}

\author{
Nur Annisa Ardhiani ${ }^{1 *}$, Dwi Sukma Ardyanti ${ }^{1}$, Ade Suryanda ${ }^{1}$ \\ ${ }^{1}$ Universitas Negeri Jakarta, Jl. Rawamangun Muka, RT.11/RW.14, Rawamangun, Pulo Gadung, Kota \\ Jakarta Timur, Daerah Khusus Ibukota Jakarta 13220
}

\section{Kata Kunci:}

Ekosistem lamun, Padang lamun, Hewan Asosiasi

\begin{abstract}
Abstrak
Ekosistem lamun banyak dijumpai di daerah estuary dan memiliki produktivitas tinggi. Ekosistem ini memiliki beragam hewan asosiasi yang memanfaatkan padang lamun untuk menunjang aktivitas hidup. Sayangnya, kondisi tutupan padang lamun di Indonesia masih tergolong kurang baik. Penelitian ini bertujuan menganalisis peran padang lamun terhadap hewan asosiasi di perairan Indonesia dengan menggunakan metode studi literatur. Ekosistem lamun dengan kondisi baik memiliki hewan asosiasi yang beragam, seperti krustasea, moluska, ikan, echinodermata, mamalia, dan reptil. Hewan asosiasi memanfaatkan padang lamun yang kaya energi biomassa sebagai tempat mencari makan, memijah dan mengasuh larvanya hingga juvenile. Padang lamun mampu menahan ombak sehingga juga berfungsi sebagai tempat berlindung larva dan hewan-hewan asosiasi di ekosistem lamun. Bentuk asosiasi hewan dengan padang lamun tergolong dalam asosiasi positif yaitu diperkirakan terjadi ketergantungan antara lamun dengan hewan asosiasi, sehingga diharapkan ada tindakan yang dapat memperbaiki kondisi luas tutupan padang lamun di Indonesia agar berbagai hewan asosiasi di padang lamun mampu memanfaatkan peran padang lamun dengan optimal.
\end{abstract}

Keywords:

Seagrass ecosystem, Seagrass bed, Animal Association

\begin{abstract}
Seagrass ecosystems are often found in estuary areas and have high productivity. This ecosystem has a variety of animal associations that use seagrass beds to support life activities. Unfortunately, the condition of seagrass cover in Indonesia is still relatively poor. This study aims to analyze the role of seagrass beds in association animals in Indonesian waters by using literature study methods. Seagrass ecosystems with good conditions have diverse animal associations, such as crustaceans, molluscs, fish, echinoderms, mammals, and reptiles. Associated animals utilize seagrass fields that are rich in biomass energy as a place to find food, spawn and nurture larvae to juveniles. Seagrass beds are able to hold the waves so that they also function as a shelter for larvae and associated animals in the seagrass ecosystem. The form of animal association with seagrass is classified as positive association, it is estimated that there is a dependency between seagrass and associated animals, so it is hoped that there are actions that can improve the condition of seagrass cover in Indonesia so that various animal associations in seagrass are able to utilize the role of seagrass optimally.
\end{abstract}

*Penulis koresponden: NurAnnisaArdhiani_1304617011@mhs.unj.ac.id 


\section{PENDAHULUAN}

Ekosistem lamun terdiri dari komunitas padang lamun yang di dalamnya terjadi hubungan timbal balik antara komponen abiotik dan biotik. Padang lamun merupakan hamparan tumbuhan lamun yang menutupi suatu area laut dangkal yang terdiri dari satu jenis maupun berbagi jenis lamun dengan kerapatan yang beragam (Sjafrie, et al. 2018). Ekosistem lamun sebagian besar ditemukan pada kedalaman laut antara 1-10 meter, semakin dangkal perairan maka tingkat kerapatan lamun akan semakin tinggi (Nybakken 1992). Ekosistem ini memiliki karakteristik komunitas yang terdiri dari tumbuhan lamun dengan morfologi daun seperti pita dan dengan rhizome yang berada di dalam substrat berupa pasir, lumpur, dan puing karang.

Padang lamun mempunyai peran penting untuk kehidupan hewan laut yang berada di perairan dangkal. Peran padang lamun diantaranya sebagai tempat untuk berlindung, mecari makan, dan penghasil energi pada ekosistem lamun. Padang lamun tentu mempunyai peran ekosistem untuk ikan di wilayah perairan dangkal karena peran lamun sebagai tempat berlindung untuk ikan-ikan kecil dan tempat mencari makan (Adrim 2006). Hal ini diperkuat dengan penelitian di kepulauan Virgin, West Indies mendapatkan hasil bahwa lamun mampu menarik ikan kakatua menuju lamun yang telah ditanam dekat terumbu karang sebagai sumber makanan (Randall 1965).

Ekosistem padang lamun banyak dijumpai pada daerah estuary perairan tropis dan merupakan salah satu ekosistem pesisir dengan tingkat produktivitas yang tinggi (Azkab 2014, Tangke 2010). Selain tingkat produktivitas yang tinggi, padang lamun juga memiliki konsentrasi fauna asosiasi yang tinggi (Azkab 2014). Padang lamun di Indonesia didominasi oleh spesies Thalassia hemprichii dan Enhalus oroides yang diantaranya berperan sebagai habitat biota asosiasi, tempat mencari makanan, tempat perkembangbiakan, dan tempat berlindung hewa-hewan asosiasi yang ada di dalam ekosistem lamun. Hewan-hewan laut yang melakukan asosiasi terhadap ekosistem lamun diantaranya yaitu kepiting dan udang yang termasuk pada kelas krustasea karena mempunyai peran penting dalam rantai makanan (Pratiwi 2010). Selain itu juga terdapat ikan-ikan yang melakukan asosiasi terhadap padang lamun. Kelimpahan ikan sangat berpengaruh pada bertambahnya biomassa lamun (Springer and Woodburn 1960). Sehingga tingginya biomassa pada padang lamun maka kelimpahan ikan menjadi tinggi. Kajian ini bertujuan menganalisis peran padang lamun bagi hewan asosiasi pada ekosistem lamun.

\section{METODE PENELITIAN}

Metode yang digunakan dalam penyusunan artikel ini adalah metode studi literatur dengan membaca, mempelajari, mengkaji, dan menganalisis literatur-literatur yang berhubungan dengan ekosistem lamun, peran padang lamun, dan hewan asosiasinya di Indonesia.

\section{HASIL DAN PEMBAHASAN}

Kondisi padang lamun yang baik sangat diperlukan untuk mendukung kehidupan hewan asosiasi. Kondisi padang lamun yang baik dapat terlihat dari presentase luasan tutupan dimana semakin tinggi persentase luas tutupan maka semakin baik kondisi padang lamun tersebut, sehingga kehidupan hewan yang berasosiasi lebih beranekaragam. Kondisi padang lamun di Indonesia berbeda pada wilayah daerah perairannya.

Menurut hasil penelitian yang telah dilakukan oleh Oseanografi LIPI pada tahun 2017 di wilayah Wakatobi dan Lombok mengatakan bahwa kondisi padang lamun di Indonesia masih kurang baik karena tutupan hanya mencapai $40 \%$ sesuai dengan presentase luas tutupan pada Keputusan Menteri (Kepmen) Lingkungan Hidup Nomor 200 Tahun 2004. Hal ini dipengaruhi akibat adanya reklamasi, kawasan industri, dan pemukiman yang tidak menjaga lingkungan dipesisir pantai dari aktivitas manusia (Sjafrie, et al. 2018). Namun pada hasil penelitian yang telah dilakukan antara P2O-LIPI dan Kementerian Kelautan dan Perikanan di wilayah perairan timur Indonesia dari data yang telah diperoleh pada tahun 2015, 2016, dan 2017 mendapatkan hasil bahwa kondisi padang lamun baik dimana mendapatkan hasil tutupan lamun > 60\% (Kementrian Lingkungan Hidup (KEMENLH) No. 200 2004). Hal ini dibuktikan dari data yang didapatkan jumlah jenis spesies pada perairan timur di Indonesia beragam dan mencapai 10 jenis spesies dan juga kondisi lamun pada perairan timur belum terjadi perubahan 
lingkungan namun pemantauan harus tetap dilakukan untuk melihat kondisi padang lamun yang mempunyai peran penting untuk hewan yang berasosiasi (PWD (Pusat Penelitian Oseanografi) 2017). Hewan-hewan yang berasosiasi di padang lamun di antaranya yaitu ikan-ikan kecil, krustasea, penyu, dan dugong.

Presentase luas tutupan padang lamun dari data monitoring yang di lakukan LIPI pada tahun 2015, 2016, dan 2017 secara keseluruhan padang lamun di Indonesia mempunyai rata-rata kondisi yang kurang baik. Hal ini dapat mempengaruhi jumlah keanekaragaman hewan yang berasosiasi di padang lamun pada perairan Indonesia.

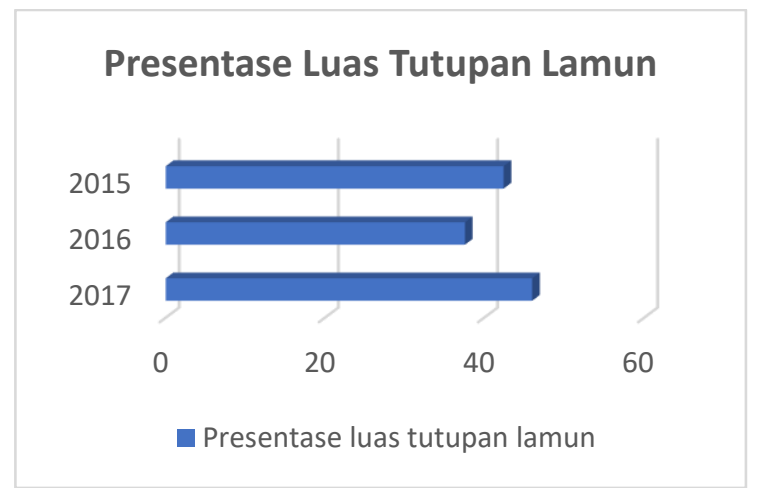

Gambar 1. Grafik presentase luas tutupan lamun di perairan Indonesia (Sjafrie, et al. 2018)

Jika dilihat pada grafik di atas maka terjadi peningkatan pada luasan tutupan padang lamun di perairan Indonesia namun masih masuk kondisi kurang baik karena belum melebihi dari 60\%. Hewan-hewan yang berasosiasi di padang lamun di antaranya yaitu ikan-ikan kecil, krustasea, penyu, dan duyung.

\section{Komunitas Hewan Asosiasi Pada Padang Lamun}

Berdasarkan penelitian yang dilakukan oleh Kikuchi \& Peres (1973) dan Direktur Konservasi dan Keanekaragaman Hayati Laut (2016), terdapat beberapa unit dan struktur kategori hewan asosiasi yang berkomunitas di padang lamun. (1) Hewan epifit yang hidup, menempel, bergerak, atau hinggap sementara pada daun lamun seperti diatom bentik yang tumbuh berkembang pada daun lamun atau pada bagian permukaan daun yang didominasi oleh epifit, epifauna dan detritus; (2) Hewan yang melekat pada rhizome lamun seperti Polichaeta dan Amphipoda; (3) Hewan bergerak yang beraktivitas di bawah atau diantara daun lamun, seperti pisces, crustacea, cephalopoda, dan Ekhinodermata; (4) Hewan yang hidup di atas daun atau di dalam sedimen lamun, seperti epibentik dan moluska.

Hewan epifit yang hidup pada Zostera terdiri dari Gastropoda, Amphipoda, Isopoda, dan Polichaeta. Produktivitas tinggi pada padang lamun sebagian disebabkan oleh aktivitas invertebrata epifit yang mendetritus lamun dan menyediakan makanan untuk hewan yang lebih besar (Jernakoff and Nielsen 1998). Gastropoda (keong) berasosiasi dengan baik terhadap ekosistem lamun dalam proses fotosintesis lamun dan berperan sebagai detritus serasah daun lamun (Sianu, Sahami and Kasim 2014). Demikian pula Amphipoda dan Isopoda yang memakan detritus dan rimpang lamun (Aswandy 2008). Secara umum, hewan yang hidup di bagian dasar atau sedimen merupakan penghuni tetap sedangkan yang berada di ujung daun merupakan hewan pencari makan berupa epifit flora pada lamun, contohnya berbagai jenis mikroalgae (Azkab 2000).

Hewan yang hidup beraktivitas di atas dan diantara daun lamun bervariasi. Krustasea seperti Periclimenes sp. ditemukan di sela-sela daun lamun Enhalus oroides, sementara kepiting dan udang juga diketahui berasosiasi dengan baik terhadap ekosistem lamun (Pratiwi 2010). Mamalia seperti dugong dan penyu menjadikan lamun sebagai sumber makanannya (Sjafrie, et al. 2018). Asosiasi pisces pada padang lamun memiliki banyak bentuk, diantaranya sebagai habitat tetap, penghuni saat memijah, penghuni saat juvenile, dan sebagai tempat singgah sementara. Kelompok Ekhinodermata yang banyak dijumpai daerah padang lamun antara lain Bintang laut (Archaster, Linckia), Lili Laut, Teripang (Holoturia), dan Bulu Babi (Diadema). Beberapa bulu babi yang ditemukan di padang lamun anatara lain Diadema savignyi, Echinotrix calamaris, Diadema setosum (Sadam, Emiryati and Ira 2019, Direktur Konservasi dan Keanekaragaman Hayati Laut 2016). Cephalopoda seperti cumi-cumi diketahui memiliki pergerakan yang tinggi di antara atau di bawah daun lamun (Azkab 2014). 


\section{Padang Lamun Sebagai Tempat Mencari Makan Hewan Asosiasi}

Padang lamun merupakan tempat yang digunakan oleh hewan yang berada diperairan dangkal untuk mencari makan seperti ikan, krustasea, ekhinodermata, dan mamalia. Padang lamun menyediakan habitat yang kompleks secara struktural dan kaya makanan yang mendukung keanekaragaman ikan (Wasserman, et al. 2020). Ikan-ikan yang memakan lamun dapat ditemukan pada perairan karibia (Randall 1965). Hal ini telah dibuktikan dari penelitiannya yang menanam lamun jenis Thalassia sp. dan Cymodocea sp. pada wilayah dekat terumbu karang yang mengundang kedatangan ikan kakatua (Scarus sp.) yang kemudian lamun tersebut habis daunnya dan hanya bagian pangkalnnya.

Terdapat jenis ikan lain sebagai pemakan lamun yaitu Acanthurus babianus, Acanthurus cioerubus, Acanthurus chirugus, Kyphosus sextatrix, dan Kyphosus incisor. Jenis ikan Hemiramphus brasiliensis dan Siganus canaliculatus merupakan pemakan utama untuk lamun Tahalassia hemprichii, didapatkan dari penelitian pada bagian lambungnya terdapat kandungan dari jenis lamun tersebut (Adrim 2006).

Kondisi padang lamun yang baik dapat memenuhi kebutuhan hidup berbagai jenis moluska, terutama sebagai tempat mencari makan (Arbi 2012). Ekhinodermata seperti bulu babi memanfaatkan padang lamun sebagai tempat untuk mencari makan dan secara langsung berperan sebagai pemakan daun lamun (Sadam, Emiryati and Ira 2019). Selain itu, krusatasea juga memanfaatkan padang lamun untuk tempat mencari makan karena beberapa jenis krustasea memakan serasah yang berada di padang lamun (Aswandy 2008). Krustasea mempunyai peran sebagai pengurai pada rantai makanan di padang lamun. Kepadatan lamun yang tinggi dapat dimanfaatkan krustasea sebagai tempat penyedia sumber makanan yang cukup tinggi (Marwati, Hamid and Arami 2018).

Penyu dan dugong merupakan hewan pemakan utama lamun yang dapat ditemukan pada padang lamun dengan kondisi baik. Hewan mamalia seperti dugong mengonsumsi semua jenis lamun sejak masih juvenile salah satunya yaitu Halodule uninervsis. Dugong merupakan hewan yang pemilih dalam mencari makan lamun di tempat yang mempunyai luas tutupan yang baik (Azkab 2014). Hal ini menyebabkan dugong sebagai indikator untuk kondisi baik pada padang lamun. Sementara pada hewan reptil yaitu penyu hijau memakan lamun daun muda dari jenis lamun Thalassia testudinum yang dilakukan pada saat usia dewasa karena penyu mempunyai bentuk mulut yang tidak bergigi dan pencernaan yang lambat sehingga hanya mampu untuk memakan lamun daun muda (Bjorndal 1980).

\section{Padang Lamun Sebagai Tempat Memijah dan Mengasuh Hewan Asosiasi}

Salah satu fungsi ekologis padang lamun adalah sebagai tempat pemijahan dan daerah asuhan bagi hewan asosiasi yang hidup di dalamnya. Padang lamun merupakan daerah yang digunakan sebagai tempat fase pemijahan bagi sebagian besar organisme laut, kemudian larva yang menetas akan menghuni padang lamun sebagai daerah asuhan hingga menjadi juvenile yang kemudian bermigrasi ke laut lepas dan akan kembali lagi ke padang lamun untuk memijah kembali (Riniatsih 2016).

Padang lamun memiliki karakteristik berupa arus yang tenang dan teduh sehingga sangat disukai oleh berbagai jenis organisme laut, khususunya ikan yang menggunakannya sebagai tempat pembesaran (Riniatsih 2016). Padang lamun adalah area pemijahan yang penting bagi banyak spesies ikan laut (Wasserman, et al. 2020). Ikan juvenile secara rutin ditemukan pada kepadatan yang lebih tinggi di padang lamun daripada di substrat yang tidak tervegetasi disekitarnya (Blandon and Ermgassen 2014). Apogon margaritroporus merupakan salah satu jenis ikan yang hidup menetap dengan memijah dan menghabiskan sebagian besar hidupnya di padang lamun, sedangkan Siganus sp. hidup di padang lamun hanya pada saat juvenile (Direktur Konservasi dan Keanekaragaman Hayati Laut 2016).

Hewan asosiasi lain yang memanfaatkan padang lamun adalah Ekhinodermata, moluska, dan krustasea. Padang lamun berperan penting sebagai tempat asuhan (nursery ground) larva Ekhinodermata agar tidak tersapu air laut dan sebagai tempat pemijahan (spawning ground). Larva Ekhinodermata yang ditemukan pada padang lamun merupakan larva yang terapung atau bergerak bebas (Jumanto, Pratomo and Muzahar n.d.). Moluska memanfaatkan padang 
lamun yang memiliki kondisi baik sebagai tempat perkembangbiakan dan tempat membersarkan anakan (Arbi 2012). Krustasea seperti udang dan kepiting memanfaatkan padang lamun sebagai tempat memijah dan tempat membesarkan larva hingga juvenile (Marwati, Hamid and Arami 2018).

\section{Lamun Sebagai Tempat Berlindung Hewan Asosiasi}

Padang lamun juga digunakan sebagai tempat berlindung untuk hewan-hewan seperti ikan-ikan kecil dan hewan krustasea hal ini karena lamun memiliki kemampuan untuk stabilisasi sendimen dari arus dan dapat mengurangi dampak gelombang (Blandon and Ermgassen 2014). Kerapatan tutupan padang lamun yang tinggi mampu menahan gelombang ombak, sehingga air laut yang berada pada padang lamun menjadi tenang seperti pada penelitian yang dilakukan oleh Orth dan Heck (1980) di Teluk Chesepeake, Amerika Serikat mendapatkan hasil ikan akan lebih beraneka ragam pada wilayah padang lamun yang mempunyai kerapatan vegetasi yang tinggi. Hal ini yang membuat padang lamun menjadi tempat berlindung yang baik untuk ikan-ikan kecil. Padang lamun juga mampu menghasilkan bahan organik dan energi untuk substrat pada biota untuk tempat pemijahan larva beberapa jenis ikan dan cephalopoda (Azkab 2014).

Ekhinodermata, dan moluska juga menjadikan padang lamun sebagai tempat berlindung. Moluska dan ekhinodermata berlindung di bawah tutupan padang lamun untuk menghindari serangan dari pemangsa atau predator (Arbi 2012, Sadam, Emiryati and Ira 2019).

\section{Sebaran Peran dan Bentuk Asosiasi Padang Lamun Terhadap Hewan Asosiasi}

Pada padang lamun yang memiliki kondisi yang baik dapat ditemukan komunitas berbagai hewan asosiasi diantaranya krustasea, moluska, ikan, ekhinodermata, mamalia, dan reptil. Hewan-hewan asosiasi tersebut memanfaatkan padang lamun sebagai tempat mencari makanan, memijah dan mengasuh, serta tempat untuk berlindung. Berikut diagram sebarannya.

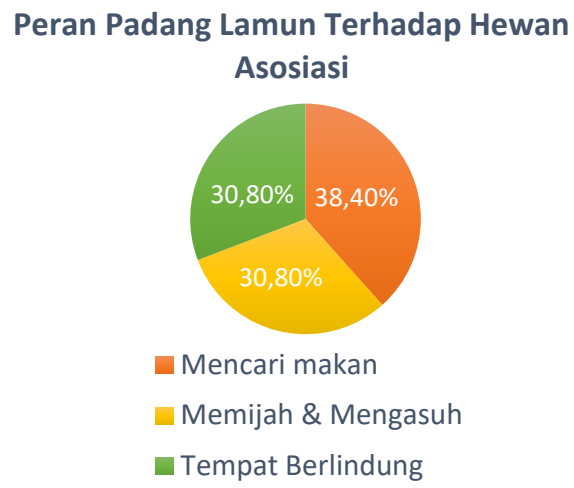

Gambar 2. Diagram persentase sebaran peran padang lamun bagi hewan asosiasi

Berdasarkan kajian peran padang lamun yang telah dilakukan dapat terlihat tingginya peran peadang lamun dalam menunjang kehidupan hewan asosiasi yang terdapat pada ekosistem lamun, sehingga bentuk asosiasi hewan di padang lamun tergolong dalam asosiasi positif yaitu dapat diperkirakan terjadi ketergantungan antara lamun dengan hewan asosiasi.

\section{PENUTUP}

Kondisi ekosistem lamun dengan padang lamun yang baik memiliki hewan asosiasi yang beragam. Kondisi padang lamun yang baik memiliki luas tutupan lamun $>60 \%$ seperti yang ditemukan pada perairan timur Indonesia, namun jika melihat keseluruhan rata-rata luas tutupan padang lamun wilayah perairan Indonesia memiliki kondisi kurang baik.

Padang lamun berperan sebagai tempat mencari makan, tempat memijah, mengasuh, dan tempat berlindung bagi hewan asosiasi. Hewan asosiasi yang ditemukan di padang lamun antara lain krustasea, moluska, ikan, ekhinodermata, mamalia, dan reptil. Hewan asosiasi memanfaatkan padang lamun yang kaya energi biomassa sebagai tempat mencari makan, memijah dan mengasuh larvanya hingga juvenile. Selain itu, penyu memanfaatkan lamun sebagai makanan saat usia dewasa. Padang lamun mampu menahan arus ombak sehingga juga berfungsi sebagai pelindung larva dan hewan-hewan asosiasi di ekosistem tersebut.

Padang lamun mempunyai peran penting dalam menunjang kehidupan hewan asosiasi yang terdapat pada ekosistem lamun, maka bentuk asosiasi hewan dengan padang lamun 
dapat tergolong dalam asosiasi positif. Dengan demikian, diharapkan ada tindakan yang dapat memperbaiki kondisi luas tutupan padang lamun di Indonesia agar berbagai hewan asosiasi di padang lamun mampu memanfaatkan peran padang lamun dengan optimal.

\section{DAFTAR PUSTAKA}

Adrim, M. 2006. "Asosiasi Ikan di Padang Lamun." Oseana, 31(4) 1-7.

Arbi, U.Y. 2012. "Komunitas Moluska Di Padang Lamun Pnatai Wori, Sulawesi Utara." Jurnal Bumi Lestari, 12(1) 55-65.

Aswandy, I. 2008. "Krustasea Sebagai Konsumen di Padang Lamun." Oseana, 33(1) 1-9.

Azkab, M.H. 2000. "Epifit Pada Lamun." Oseana, 25(2) 1-11.

Azkab, M.H. 2014. "Peran Padang Lamun Untuk Kehidupan Hewan Asosiasi." Oseana, 39(2) 49-54.

Bjorndal, K. A. 1980. "Nutrition and grazing behavior of the green turtlle Chelonia mydas." Mar. Biol, (56) 147-154.

Blandon, A., and P. Ermgassen. 2014. "Quantitative estimate of commercial fish enhancement by seagrass habitat in southern Australia." Estuarine, Coastal and Shelf Science 141: 1-8.

Direktur Konservasi dan Keanekaragaman Hayati Laut. 2016. Ekosistem Lamun di Taman Wisata Perairan Kepulauan Anambas. Pekanbaru: Loka Kawasan Konservasi Perairan Nasional Pekanbaru.

Heck, K., and R. Orth. 1980. "Seagrass Habitats: The Roles Of Habitat Complexity, Competition And Predation In Structuring Associated Fish Ans Motile Macroinvertebrate Assemblages." Estuarine Perspectives 449-464.

Jernakoff, P., and J. Nielsen. 1998. "Plantanimal association in two species of seagrass in Western Australia." Aquatic Botany 60: 359-376.

Jumanto, A. Pratomo, and Muzahar. n.d. "Struktur Komunitas Echinodermata di Padang Lamun Perairan Desa Pengudang Kecamatan Teluk Sebong Kabupaten Bintan Provinsi Kepulauan Riau."

Kementrian Lingkungan HIdup (KEMENLH) No. 200. 2004. Kriteria Baku Kerusakan Alam dan Pedoman Penentuan Status Padang Lamun. Jakarta.
Kikuchi, T., and J. Peres. 1977. Consumer ecology of seagrass beds in seagrass ecosystem;: a scientific perspective. New York: Marcel Dekker, Inc.

Marwati, A. Hamid, and H. Arami. 2018. "Keanekaragaman Jenis Krustasea Pada Padang Lamun Di Perairan Tanjung Tiram Kecamatan Moramo Utara Kabupaten Konawe Selatan." Jurnal Managemen Sumber Daya Perikanan, 3(2) 83-91.

Nybakken, J.W. 1992. Biologi Laut Suatu Pendekatan Ekologis. Jakarta: Gramedia Pustaka Utama.

Pratiwi, R. 2010. "Asosiasi Krustasea di Ekosistem Padang Lamun Perairan Teluk Lampung." ILMU KELAUTAN, 15(2) 66-76.

PWD (Pusat Penelitian Oseanografi). 2017. Ekosistem Padang Lamun di Indonesia Masih Kurang Bagus. Juny 07. Accessed Juny 24, 2020. http://lipi.go.id/siaranpress/ekosistempadang-lamun-di-indonesia-masihkurang-bagus/18396.

Randall, J.E. 1965. "Grazing effect on seagrass by herbivorous reef fishes in the West Indies." Ecology 225-260.

Riniatsih, I. 2016. "Struktur Komunitas Larva Ikan Pada Ekosistem Padang Lamun Di Perairan Jepara." Jurnal Kelautan Tropis, 19(1) 21-28.

Sadam, L., Emiryati, and Ira. 2019. "Keanekaragaman Bulu Babi (Echinoidea) Pada Kawasan Lamun Di Perairan Desa Langara, Kecamatan Wawonii Barat Kabupaten Konawe Kepulauan." Sapa Laut, 4(3) 13-122.

Sianu, N., F. Sahami, and F. Kasim. 2014. "Keanekaragaman dan Asosiasi Gastropoda dengan Ekosisitem Lamun di Perairan Teluk Tomini." Jurnal Ilmiah Perikanan dan Kelautan, 2(4) 156-163.

Sjafrie, N., U. Hernawan, B. Prayudha, I. Supriyadi, M. Iswari, Rahmat, K. Anggraini, S. Rahmawati, and Suyarso. 2018. Status Padang Lamun Indonesia 2018. Jakarta: Pusat Penelitian Oseanografi LIPI.

Springer, V., and K. Woodburn. 1960. "An ecological study of the fishes of the Tampa Bay area." Profess. Pap. Ser. Fla. Sta. Board Consrv 104. 
Tangke, U. 2010. "Ekosistem Padang Lamun (Manfaat, Fungsi, dan Rehabilitasi)." Jurnal Ilmiah Agribisnis dan Perikanan (agrikan UMMU-Ternate), 3(1) 9-29.

Wasserman, R., A. Whitfield, S. Deyzel, N. James, and S. Hugo. 2020. "Seagrass (Zostera capensis) bed development as a predictor of size structured abundance for a ubiquitous estuary-dependent marine fish species." Estuarine, Coastal and Shelf Science 238: 1-9. 